\title{
MAXH KPATEIN EN LA GUERRA DE CORINTO: LAS BATALLAS HOPLÍTICAS DE NEMEA Y CORONEA (394 A.C.)
}

POR

\section{CÉSAR FORNIS}

\begin{abstract}
Al término del combate, se podía ver la tierra donde se enfrentaron empapada en sangre, cadáveres de amigos y enemigos que yacían unos junto a otros, escudos destrozados, lanzas rotas, puñales sin sus vainas: unos en el suelo, otros en los cadáveres, otros aún en las manos

(Jenofonte, Agesilao, 2.14 [sobre Coronea]; trad. O. Guntiñas)
\end{abstract}

\section{RESUMEN - ABSTRACT}

En este artículo ofrecemos una reconstrucción y un análisis del marco geopolítico, basado en el conjunto de las fuentes literarias existentes y no sólo en el contemporáneo pero sesgado relato de Jenofonte en sus Helénicas, de dos de las más conspicuas batallas campales del mundo griego antiguo: las de Nemea y Coronea, ambas trabadas en el verano de 394 a. C., durante la llamada guerra de Corinto, y ambas ilustrativas y paradigmáticas de lo que era un choque entre dos falanges de hoplitas.

In this paper we offer a reconstruction and an analysis of the geopolitical framework, founded in the whole literary sources and not only in the contemporary but biased account of Xenophon's Hellenica, of two of the most conspicuous pitched battles of the ancient Greek world, namely those of Nemea and Coroneia, both of them were fighted in 394 B. C., during the so-called Corinthian War, and both of them are illustrative and paradigmatic of what a clash between two hoplite phalanxes means.

\section{PALABRAS CLAVE - KEY WORDS}

Hoplita, Falange. Batalla campal. Nemea. Coronea. Guerra de Corinto. Hegemonía espartana.

Hoplite. Phalanx. Pitched battle. Nemea. Coroneia. Corinthian War. Spartan hegemony.

No constituye novedad alguna la afirmación de que la guerra fue compañera inseparable del hombre griego a lo largo de su fértil pero convulsa historia ${ }^{1}$. Vencer, aplastar al enemigo

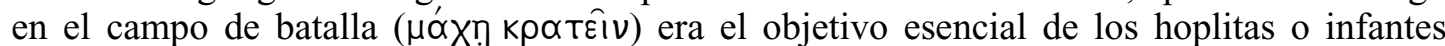

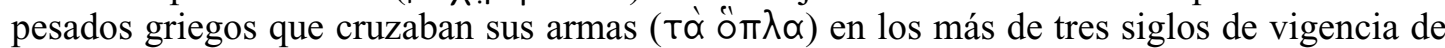
los usos y normas no escritas que conformaban el singular éthos hoplítico.

En el verano del año 394, en el curso de la llamada guerra de Corinto, que durante un decenio enfrentó a Esparta con una poderosa coalición integrada por Atenas, Beocia, Argos y

1 K. J. BELOCH (citado por Parke, 1933: 228) recordaba que entre 431 y 346 hubo únicamente treinta y dos años sin que el solar helénico viera ningún conflicto de entidad. 
Corinto, tuvieron lugar dos de las más conspicuas batallas campales de la historia de Grecia, tanto por el tamaño y naturaleza de los ejércitos implicados como por lo que se hallaba en juego, nada menos que la hegemonía en la Hélade. Se trata de las batallas de Nemea y Coronea, la primera trabada en la Corintia, la segunda en Beocia. En este artículo pretendemos, a través de un análisis de las fuentes literarias, acercarnos sucesivamente a estos grandes choques en la medida en que ambos constituyen ilustrativos ejemplos, casi paradigmáticos, de lo que representaba una batalla hoplítica en la Grecia clásica ${ }^{2}$, bien es verdad que cada una con sus matices propios, pero al mismo tiempo con la intención de ahondar en su significación dentro del convulso contexto geopolítico de principios del siglo IV.

\section{LA BATALLA DE NEMEA}

Después de varias escaramuzas en Grecia central durante la primavera de 394, que respondían a una inquietud beocia por reforzar su frontera norte tras la exitosa campaña en Haliarto del año anterior ${ }^{3}$, la proximidad de la estación estival alentará proyectos más ambi-

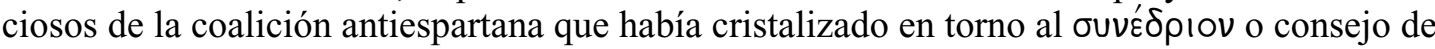
Corinto $^{4}$. Reunidos en dicha ciudad los representantes de los cuatro estados miembros para determinar la mejor manera de conducir la guerra contra los lacedemonios, Jenofonte ha preservado el recuerdo de la sugerente propuesta del corintio Timolao en cuanto a la necesidad de proceder a una rápida invasión de Lacedemonia que impidiera a los espartanos ir sumando aliados en su camino desde el sudeste del Peloponeso hasta el istmo de Corinto. El perspicaz político corintio, antaño colaborador de la causa espartana — según el anónimo de Oxirrinco había mudado su lealtad «por motivos personales» ${ }^{5}-$, ilustra sus palabras con dos símiles que comparan a los espartanos primero con un río, que si en su nacimiento es sencillo de vadear, crece en corriente e intensidad a medida que se le agregan afluentes, y luego con las avispas, más fáciles de destruir si se pega fuego al avispero antes de que salgan y piquen 6 .

2 Al margen de los estudios que se irán desgranando del presente artículo, la hoplomachía es abordada con un carácter general en Ducrey, 1985 (en particular el capítulo II), Ober, 1996 y sobre todo Lazenby, 1989 y Hanson, 1989 y 1991, que además recogen lo sustancial de la literatura moderna anterior. Para el origen, evolución y difusión del armamento de los hoplitas - y de otros tipos de soldados - continúa siendo fundamental Snodgrass, 1967, muy especialmente el capítulo III. Tal y como mostró Lissarrague, 1990, la figura del hoplita se erige en el eje central de las escenas representadas en la cerámica ática, transfiguración del papel nuclear que en la vida social de la polis —en este caso la ateniense- tenía el ciudadano propietario capaz de costearse sus propias armas.

3 El inesperado triunfo beocio en Haliarto frente a las fuerzas lacedemonias codirigidas por Lisandro y Pausanias, con las consiguientes repercusiones internas en el seno de la confederación presidida por Tebas, se examina con minuciosidad en las tesis doctorales de Cook, 1981: 280-300 y Pascual González, 1995: 709-755.

4 D.S. 14.82. Jenfofonte pasa por alto la constitución del sinedrio dentro del curso natural o cronológico de los acontecimientos, si bien es cierto que en $H G$. 3.5.2 hallamos una breve sentencia anticipatoria.

5 Hel. Oxy. 7.3; sigo y cito la edición de Vittorio Bartoletti para Teubner (Leipzig, 1959).

6 Accame, 1951: 81-83 sospecha que el discurso de Timolao fue inventado por Jenofonte e insertado de una forma artificiosa mucho tiempo después, cuando la invasión de Epaminondas tras la batalla de Leuctra mostró el camino para humillar a Esparta, pero en 394 ésta aún no había sido vencida en campo abierto. En opinión del historiador italiano, Jenofonte, que se había retirado a Corinto una vez perdida su villa de Escilunte en 370, habría pretendido en este pasaje exculpar a quienes le habían acogido de la responsabilidad de la derrota, mientras que en otros lugares, como en el del cierre de las puertas de la ciudad a los aliados que huían de la batalla (vid. infra), buscaba minimizar las diferencias entre los espartanos y los corintios, tradicionales aliados antes y después de esta guerra. Bajo nuestro punto de vista es cierto que Jenofonte mantenía estrechos vínculos con los círculos aristocráticos corintios, y en especial con la facción filolaconia, por la que no oculta su entusiasmo, de ahí lo extraño de justificar innecesariamente las acciones de la facción antilaconia, que él consideraba en buena medida responsable de la guerra contra Esparta y de las desgracias que había padecido la ciudad. Tampoco les falta razón a Cook, 1981: 313 y Salmon, 1984: 350: n. 34, en su crítica a la tesis de Accame, al afirmar que logros como el de Epaminondas pueden ser concebidos antes de ser llevados a efecto y que si los aliados pretendían únicamente asegurar el Istmo, carecería de sentido haber avanzado más hacia el sur, hasta Nemea. Pronunciara o no 
A pesar de que la idea gozó de una excelente acogida, de una parte la rapidez de movimientos de los lacedemonios, a cuyos oídos llegarían los rumores de los planes y preparativos enemigos, y de otra las rencillas internas de los coligados por ver quién asumía la jefatura y por determinar qué disposición y profundidad adoptarían las falanges, impidieron la puesta en práctica de una estrategia que aún habría de esperar veinticuatro años para cobrar vida de la mano del tebano Epaminondas 7 . Para cuando se decidieron y marcharon hacia el sur a través de la Argólide, sólo pudieron alcanzar Nemea, pues los lacedemonios y sus aliados se encontraban ya en Sición ${ }^{8}$.

En efecto, afrontada la evidencia de que Agesilao, llamado de su campaña asiática, no podría llegar a tiempo para el choque y de los preparativos enemigos, los éforos dictaron la orden de movilización del ejército y enseguida se fueron incorporando los aliados al ejército lacedemonio en su marcha a través de Arcadia hacia el istmo de Corinto, todos salvo los fliasios, que

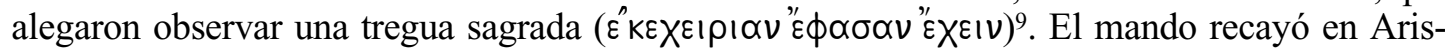
todemo, miembro de la dinastía Agíada y tutor de Agesípolis, todavía menor de edad, a quien correspondía el trono dentro de esta casa real en razón del exilio de su padre Pausanias ${ }^{10}$.

Mientras los coligados y sus aliados avanzaron desde la ciudad de Nemea, probablemente a lo largo de la ribera izquierda del río homónimo, los lacedemonios y los suyos hicieron lo propio desde Sición. El encuentro tuvo lugar en terreno llano, el que requiere el desenvolvimiento de las falanges de hoplitas, entre los lechos de los ríos Rachiani (o Longopotamos) y Nemea (Fig. 1). Este último, que servía de frontera entre los estados de Sición y Corinto, será quien preste su nombre a una de las batallas de mayor renombre en la historia de Grecia — también llamada batalla de Corinto, que es como la conocieron los antiguos —, trabada en la

el corintio ese discurso, para Tuplin, 1993: 66 lo importante es la intención de Jenofonte de poner de manifiesto la fragilidad del imperio espartano. En esta misma línea, Cartledge, 1979: 280 deduce de las palabras de Timolao, como de las de los embajadores tebanos que habían logrado la alianza con Atenas un año antes, una evidente desafección de los arcadios hacia la hegemonía espartana, ya que el plan presupone atravesar Arcadia sin contratiempos en el camino hacia Lacedemonia.

7 Esto demostraría, en opinión de Tuplin, 1993: 67, el «tratamiento casi satírico» que Jenofonte hace de la propuesta del corintio al crear expectativas que se verán defraudadas.

8 X. HG. 4.2.10-13. Salmon, 1984: 350-351 presume por el contrario que los espartanos observaron en principio una estrategia diletante para dar tiempo a que Agesilao regresara y cogiera la espalda de sus enemigos, hasta que la noticia de las intenciones de éstos — difundidas presuntamente por corintios laconizantes — les obligó a actuar con resolución.

9 X. HG. 4.2.16. Los lacedemonios tomaron la ruta de Tegea y Mantinea, donde se les sumaron los contingentes arcadios, y luego prosiguieron a Sición, lugar en el que recibirían los refuerzos aqueos desde el oeste y los de la Epidauria y la Argólide desde el este (Pritchett, 1969: 79). Sobre los motivos reales de la ausencia fliasia, extraña en una larga trayectoria de colaboración con Esparta, Legon, 1967: 329-330 con n. 41 conjetura que en 394 estuviera muy reciente la stásis o conflicto interno en el seno del cuerpo cívico que desembocó en la instauración de un régimen democrático y por ello no quisieran desprenderse de tropas. Si exceptuamos este hecho y que a comienzos de la contienda Fliunte se negó a acoger una guarnición lacedemonia dentro de los muros de la ciudad, por miedo a que los espartanos promoviesen el regreso de los laconófilos exiliados (X. HG. 4.4.15), no hay signos de desafección fliasia o de incumplimiento de sus obligaciones militares para con su hegemón durante el resto de la contienda. De hecho los fliasios acabaron por solicitar una guarnición lacedemonia en 391, cuando Ifícrates causó numerosas bajas en un ataque a la ciudad (ibid.). Sin embargo, no es preciso recurrir a la teoría de una metabolè politeías y la subsiguiente implantación de una democracia - forma de gobierno extraña a una polis que tradicionalmente ha dispuesto de un ordenamiento oligárquico- para explicar la trayectoria política de Flunte en el siglo IV. Thompson, 1970 ha demostrado de manera convincente que los disturbios internos que azotaron la ciudad no nacían de una divergencia ideológica o socioeconómica, sino de la orientación de su política exterior, fundamentalmente en relación a Esparta. Con regímen democrático o sin él, Esparta no parecía satisfecha con el estado de los asuntos en Flunte, de ahí que en 384, gracias a una peculiar interpretación de la cláusula de autonomía acordada en la paz del Rey, Agesilao auspiciase el regreso de los desterrados filolaconios, así como la restitución de sus bienes, para tres años más tade, ante nuevas críticas de los otrora exiliados y aprovechando la presencia de su colega Agesípolis en la guerra olintia, dirigir personalmente un asedio de veinte meses a la ciudad que sólo cesó con la instauración de una oligarquía de perfil laconizante, entre cuyos miembros había no pocos huéspedes, amigos y clientes del rey espartano (X. $H G$. 5.3.10-17 y 21-25).

10 X. HG. 4.2.9; cf. 3.5.25. Anderson, 1970: 147 supone, y no deja de ser una suposición, que el más experimentado Dercílidas y no Aristodemo diseñaría el plan estratégico para la batalla. 
segunda mitad de julio de $394^{11}$. Antes de descender al valle hubo, empero, una escaramuza en la región abrupta de la Epiecea, fronteriza entre la Corintia y la Sicionia, como consecuencia de la cual los lacedemonios sufrieron algunas bajas a manos de tropas ligeras enemigas ${ }^{12}$.

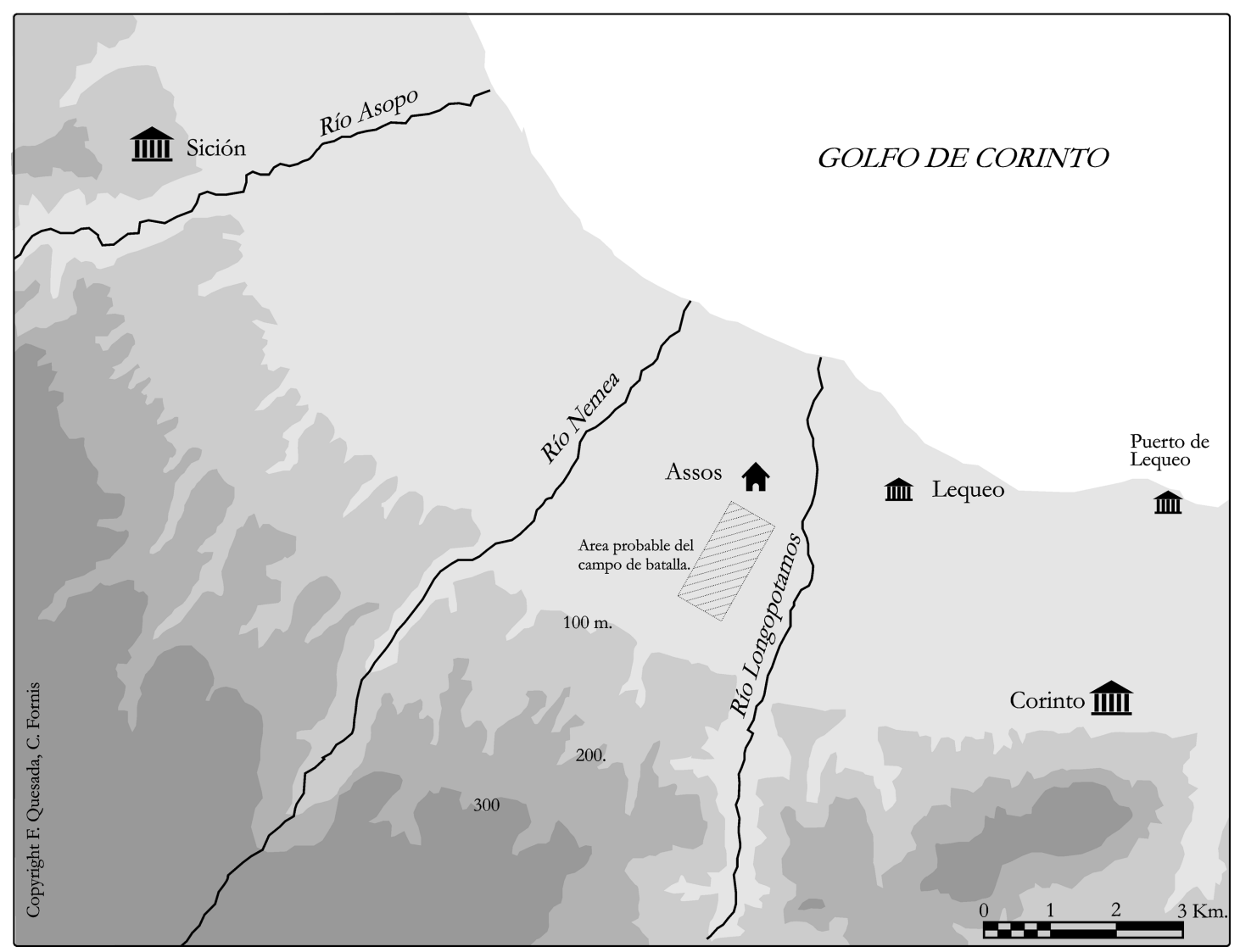

Fig. 1. Topografía del campo de batalla de Nemea (basado en Pritchett y Lazenby)

11 Véase Pritchett, 1969: 77-83 y Lazenby, 1985: 135-136 para una descripción topográfica general del área y una propuesta de identificación de los lugares donde acamparon ambos ejércitos y luego se desarrolló la batalla, más cerca del río Rachiani que del Nemea, posiblemente no lejos de la moderna aldea de Assos (hacia el punto kilométrico 10,5 de la autovía que une Corinto y Patras). Para el río Nemea como limes fronterizo entre la Corintia y la Sicionia: Str. 8.6.25 y Liv. 33.15.1. En cuanto a la cronología, el obvio terminus ante quem está marcado por el eclipse de sol del 14 de agosto, día en el que Agesilao, entonces en Anfípolis, se enteró de la noticia (X. HG. 4.3.10; Plu. Ages. 17.4). Una mayor precisión nos la aporta la alianza entre atenienses y eretrios $\left(I G \mathrm{II}^{2} 16+S I G 123\right)$, anudada en el arcontado de Eubulides, que comienza el 16 de julio de 394. Puesto que sabemos que los eubeos estuvieron en las filas de los coligados en Nemea (X. HG. 4.2.17), la batalla hubo de librarse en la segunda quincena de julio (Aucello 1964: 33 n. 18 intenta afinar aún más: en torno al 20 de julio). En contra de esta evidencia epigráfica, Accame, 1951: 65-73, seguido por Hamilton, 1979: 223, data la batalla antes de la salida del arcontado de Diofanto, esto es, antes del 15 de julio, alegando entre otras cosas que se precisaría al menos un mes para que las nuevas del enfrentamiento cubrieran los aproximadamente 450 kilómetros que dista Anfípolis de Beocia; a este argumento, por lo menos discutible (el cálculo se basa en la marcha de un ejército y no en la de un mensajero), el italiano añade otro menos plausible consistente en explicar la presencia eubea en Nemea al margen totalmente de obligaciones de tratado (pág. 58). Sin reparar tampoco en esta alianza, Cook, 1981: 314 con n. 4 aboga por una fecha a finales de junio o principios de julio, y Cartledge 1987: 361 y Buck 1998: 44 en junio.

12 X. $H G$. 4.2.14. 
Las fuerzas presentadas por ambos bandos eran muy parejas en número y más que considerables en relación con la media de un enfrentamiento hoplítico. A los seis mil hoplitas lacedemonios en origen - entre espartiatas, periecos, neodamodes y quizá esciritas ${ }^{13-}$, que constituían la médula espinal del ejército, se fueron incorporando tres mil más entre eleos, trifilios, acrorios y lasionios, otros tres mil entre trecenios, hermioneos y halieos, y mil quinientos sicionios. En total trece mil quinientos hoplitas ( $\left.\delta \pi \hat{\lambda} \imath \alpha_{1}\right)$, arropados por seiscientos

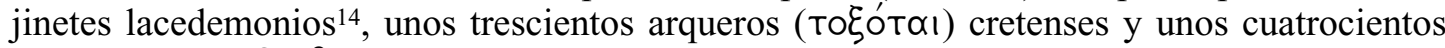
honderos ( $\sigma \phi \varepsilon \nu \delta о \nu \eta \hat{\tau} \alpha \iota)$ marganeos, letrinos y anfidolos. En el campo contrario figuraban seis mil hoplitas atenienses - a las órdenes de Trasibulo de Estiria, arquitecto de la alianza con Beocia que llevó a Atenas a la guerra con Esparta ${ }^{15}$-, siete mil argivos, cinco mil beocios - excepto los orcomenios, que habían hecho defección de la confederación un año antes gracias a la vehemente diplomacia de Lisandro ${ }^{16}$-, tres mil corintios y tres mil eubeos, que hacen un total de veinticuatro mil hombres, a los que cabe añadir un número indeterminado

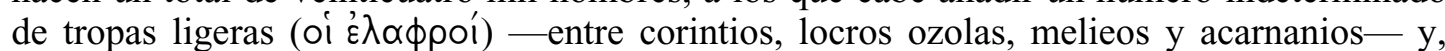
como caballería, ochocientos jinetes beocios, seiscientos atenienses, cien eubeos y cincuenta locros opuntios ${ }^{17}$.

Estas cifras recordadas por Jenofonte no concuerdan con las facilitadas por Diodoro Sículo, quien da un total de veintitrés mil hoplitas lacedemonios y aliados por quince mil de la coalición antiespartana, acompañados en ambos casos por medio millar de jinetes ${ }^{18}$. A primera vista la manera más sencilla de conciliar los dos testimonios consiste en atribuir a Diodoro el error de invertir los guarismos, de tal modo que, si en el campo lacedemonio sus quince mil se aproximan a los trece mil quinientos de Jenofonte, en el opuesto sus veintitrés mil también se acercan a los veinticuatro mil del historiador ateniense ${ }^{19}$. Pero sucede que

13 Todas las modificaciones de Cavaignac, 1925 al número y disposición de las tropas de la alianza espartana suministrados por Jenofonte parten de una premisa errónea: la imposibilidad de que hubiera seis mil hoplitas espartiatas. Pero es que se trata, como dice Jenofonte, de hoplitas lacedemonios, de los que según la práctica habitual al menos la mitad serían periecos (la endémica oliganthropía espartiata es la causa de que la presencia de periecos en el ejército fuera creciendo desde Platea, en 479 , donde son el 50\%, hasta Leuctra, en 370, donde constituyen ya el 70\%, para lo cual pueden consultarse las tablas I, III y IV de Figueira, 1986: 212-213). Luego tenemos que muy posiblemente Jenofonte contó también entre ellos a los esciritas, unos seiscientos (así por ejemplo Valzania, 1996: 40-41), y un número indeterminado de neodamodes: aunque tres mil habían partido para Asia con Agesilao, otros debieron permanecer en Esparta, quizá unos mil quinientos, como piensa Welwei, 1974: 152, que deja un total de 3300-3500 hoplitas espartiatas y periecos, más los trescientos hippeîs de la guardia real, mientras Cartledge, 1979: 280-281 reduce en un millar la cifra de neodamodes de Welwei para pasarlos al contingente de hómoioi y periecos (el autor británico cree que, dada la situación de emergencia, Esparta realizó una leva más completa que afectaría a treinta y cinco de las cuarenta y cinco clases de edad en activo, con lo que las cinco móras o batallones se compondrían de novecientos hombres [hay un ejemplo en Polibio] en lugar de los habituales seiscientos). Cozzoli, 1979: 80-82 no sólo no duda de que hubiera seis mil hoplitas y seiscientos caballeros lacedemonios en Nemea, sino que piensa que aún quedaron «qualche migliaio di fanti corazzati per la diffesa della cittá», evaluando el total de las fuerzas armadas lacedemonias entre 9600 y 11200 hoplitas y caballeros. En suma, no vemos razón alguna para rechazar la cifra global de seis mil hoplitas lacedemonios atestiguada por Jenofonte.

14 Esparta, la pólis hoplítica por antonomasia, no tenía una tradición arraigada en el mantenimiento de un bien entrenado cuerpo de caballería, todo lo contrario que los beocios, ahora en el frente enemigo, quienes siempre habían hecho la principal contribución en jinetes a las fuerzas de la liga del Peloponeso. De hecho no existió un contingente de

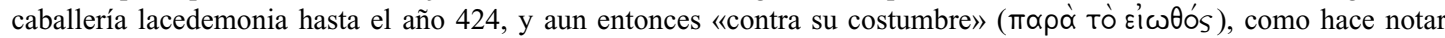
Tucídides (4.55.2), reclutando además para el mismo «a los individuos menos capaces físicamente y menos deseosos de gloria» (X. HG. 6.4.11).

15 La única fuente que lo menciona es Lisias (16.15), que se hace eco de los reproches por cobardía vertidos por el de Estiria contra sus conciudadanos justo después de la batalla, siendo uno de los últimos en abandonar el campo. Buck, 1998: 102 explica que, como estratego, Trasibulo ocupó el flanco derecho del contingente ateniense, con las cuatro tribus vencedoras, y que sus críticas hacia las seis tribus vencidas nunca fueron olvidadas por algunos de sus miembros.

16 X. $H G$. 3.5.6 y 17; Plu. Lys. 28.2.

17 X. $H G$. 4.2.16-17.

18 D.S. $14.82 .10-83.1$.

19 Así lo pensó Cavaignac, 1925: 275, contestado con buen criterio por Kromayer y Veith, 1931: 595-596. 
éste, en el recuento inicial de los aliados lacedemonios, preocupado por reducir los números del bando lacedemonio - y puede que también por engrosar los de sus rivales - a fin de acentuar la dimensión de su victoria, ha «olvidado» a los tegeatas, mantineos y aqueos, que sin embargo aparecen más adelante en el relato de la batalla. Por ello, ante la necesidad de calcular el número de hombres de estos tres contingentes, diversos estudiosos han coincidido en una estimación de nueve mil, que con la adición de los trece mil quinientos anteriores arrojarían una cifra de veintidós mil quinientos, muy cercana a los veintitrés mil reflejados por el Sículo ${ }^{20}$.

Aceptada esta evaluación, quedaría sin resolver la disparidad entre nuestras dos fuentes para el ejército de la coalición antiespartana y es aquí donde entraría en juego la hipótesis de Silvio Accame según la cual, puesto que el número de jinetes aliados que encontramos en Diodoro, unos quinientos, se asemeja al de los jinetes atenienses en Jenofonte, unos seiscientos, el historiador siciliota, o su fuente, Éforo, «se habría saltado» los contingentes de caballería aportados por beocios, calcídicos eubeos y locros opuntios, que en Jenofonte suman novecientos cincuenta, de lo que se podría colegir que quizá Diodoro habría omitido también los contingentes de hoplitas de estos tres pueblos, unos ocho mil infantes según Jenofonte — cinco mil beocios y tres mil eubeos-, con lo que harían un total de veintitrés mil, cifra muy cercana a los veinticuatro mil del historiador ateniense ${ }^{21}$. Así pues, si prescindimos de la caballería, donde los coligados doblaban en número a los espartanos y sus aliados, pero que, como suele suceder en las batallas campales de la antigua Grecia no jugó un papel relevante, en Nemea combatieron dos ejércitos de análogos efectivos y potencial.

En lo que se refiere a la disposición de los diferentes contingentes en la formación de cada bando, los lacedemonios, como era costumbre, ocuparon el ala derecha, al lado de los tegeatas, frente a los atenienses, mientras los aqueos del ala izquierda encaraban a los beocios. Según Jenofonte los coligados, con el fin de evitar verse rodeados por los lacedemonios, acordaron dar una profundidad a la falange de dieciséis filas, salvo los beocios, que la aumentaron en un número indeterminado - en la última batalla hoplítica, librada en Delio en el año 424, los tebanos habían formado en veinticinco filas, por lo que es una natural inferencia que o bien repitieron esta formación o bien la engrosaron algo más, pero aún lejos de las cincuenta filas que presentaron en su gran victoria de Leuctra ${ }^{22}$-, lo que conforma un frente de 1188 escudos sin contar los beocios y quizá unos 1388 con ellos ${ }^{23}$. Por parte de los lacedemonios y sus aliados, Jenofonte no indica la profundidad de su falange, si bien los espartanos tradicionalmente formaban en un número menor de filas - ocho por ejemplo en Mantinea, en 418, doce en Leuctra, en $371^{24}$ - lo que significa un frente más extenso que el de los enemigos y el consiguiente riesgo para éstos de verse cercados ${ }^{25}$. El lector del relato

20 La hipótesis parte de Kromayer y Veith (ibid.) y es asumida por Pritchett, 1969: 74; Anderson, 1970: 143; Roy, 1971; Hamilton, 1979: 221; Pascual González, 1995: 775-777. Para Lazenby, 1985: 136 se trata de una estimación excesiva y forzada por la exigencia de reconciliar los testimonios de Jenofonte y Diodoro, de ahí que prefiera rebajar el número a unos cinco mil, para un total del ejército hoplítico de unos dieciocho mil quinientos hombres, aunque ninguna fuente registre tal cifra. También Tuplin, 1986: 51-52 la considera exagerada, lo que unido al hecho de no encontrar convincentes otras posibles soluciones le conduce a quedarse con lo que para él es sustancial: la manipulación que hace Jenofonte de su narrativa con el fin de culpar a los tebanos de la derrota aliada, pese a lo cual el núcleo del episodio «remains perfectly acceptable».

21 Accame, 1951: 76-77.

22 Th. 4.93.4 (Delio); X. HG. 6.4.12 (Leuctra). La propensión beocia a incrementar la profundidad de la falange responde a la propia tradición y costumbres bélicas de este pueblo, como comenta Pascual González, 1995: 778-779.

23 X. HG. 4.2.18; cf. Lazenby, 1985: 138-139.

24 Th. 5.68.3 (Mantinea); X. HG. 6.4.12 (Leuctra).

25 Lazenby, 1985: 139 parece inclinarse por doce, pero añade que sus aliados no tuvieron por qué emularles. Pritchett, 1969: 76, Roy, 1971: 440 y Pascual González, 1995: 774-775 prefieren pensar que los lacedemonios y aliados adoptaron una profundidad de dieciséis filas, las mismas que sus adversarios, aunque no tenga constatación en la historia militar espar- 
jenofóntico extrae la clara impresión de que fue esta «obstinación» beocia por engrosar la falange la causa de la kúk $\lambda \omega \sigma$ Is o maniobra de envolvimiento sufrida por los atenienses durante la batalla y, consecuentemente, de la derrota confederada ${ }^{26}$.

Ya en los preámbulos del choque, Jenofonte, que no desaprovecha oportunidad alguna de zaherir a los tebanos, les presenta indolentes y timoratos mientras ocupan el ala izquierda, de cara a los espartanos, mas cuando fueron los atenienses quienes les reemplazaron - de lo que se deduce que los coligados habían acordado una rotación diaria en el mando, que según la costumbre recae en el ala derecha ${ }^{27}$ - enseguida se envalentonaron y anunciaron que los sacrificios eran favorables ${ }^{28}$. Una vez dada la voz de ataque, los beocios iniciaron el movimiento de aproximación escorándose hacia el lado derecho, arrastrando con ellos a los atenienses y demás aliados, que no querían verse aislados ${ }^{29}$. Naturalmente la intención beocia era desbordar el flanco derecho enemigo con la esperanza de que sus aliados aguantarían entretanto el empuje de los lacedemonios, pues, como es sabido, salvo imprudencia o temeridad en la persecución subsiguiente, en una batalla hoplítica se impone aquél que rompe primero el frente de sus adversarios sin perder la cohesión propia.

Al escuchar el peán cantado por el enemigo, los lacedemonios, que hasta entonces no habían podían ver a sus enemigos debido a la abundante vegetación que los separaba, se apercibieron y se movieron a su vez con la misma inclinación hacia la derecha, extendiendo notablemente su ala, tanto es así que rebasaron con creces a los atenienses de enfrente, cuatro de cuyos contingentes tribales - dos mil cuatrocientos hombres - quedaron situados de cara a los tegeatas, y girando los extremos hasta formar un ángulo recto - esto es, dibujando una letra gamma (Г)-, con el fin de envolver, aunque no por completo, a sus oponentes (Fig. 2). Esta maniobra dio el fruto esperado y la cercada falange ateniense se deshizo, de forma que los lacedemonios, que seguían en formación compacta, causaron muchas bajas entre los ate-

tana y vaya en contra de la aseveración de Jenofonte acerca de la igualdad numérica de ambos ejércitos (a semejante número de filas el bando espartano hubiera precisado de más efectivos para poder realizar la maniobra de envolvimiento).

26 Aunque Accame, 1951: 80-81 habla de negligencia beocia (nótese sin embargo, que en Leuctra, su gran victoria de 371 , los beocios formaron con una profundidad de ¡cincuenta filas! que cortaron por completo a la falange lacedemonia), para él no tuvo tanta incidencia en la derrota final como la falta de ardor ateniense en la contención de los lacedemonios, a la que Jenofonte voluntariamente habría restado relevancia. También Pascual González, 1995: 780 exculpa parcialmente a los beocios de la derrota, pero en este caso la responsabilidad la compartirían por igual con los argivos, los corintios y las cuatro tribus atenienses que encararon a los tegeatas, al no haber acudido en ayuda de las seis tribus atenienses que combatieron con los lacedemonios. Tuplin, 1993: 67 recuerda que es una ironía subrayada por Jenofonte que el modo de evitar la kýklosis fuera la razón de la demora de los coligados en el momento de llevar a la práctica el plan sugerido por Timolao (vid. supra).

27 Así, por ejemplo, Accame, 1951: 56, Pritchett, 1969: 84 y Buck, 1998: 101. Es cierto que, como aduce Cook, 1981: 320-324, la rotación en el mando es extraña en la práctica bélica griega de época clásica — sólo está documentada en la alianza ateniense y espartana de 369-, pero de qué otra forma se zanjaría la cuestión de cuáles eran las mejores tropas para, conforme a la costumbre, situarlas en el ala derecha; el otro procedimiento más atestiguado, que la ocupe el contingente del estado en cuyo territorio se combate, no parece que se aplicara aquí, pues en tal caso hubiera correspondido indiscutiblemente a los corintios. Una tercera alternativa ofrecida por Cook ( $\mathrm{ibid}$.), la de que atenienses y beocios se disputaron la hegemonía, resulta demasiado aleatoria, sin eco en las fuentes y mediatizada por la tesis general de la autora de que los beocios «concebían la guerra como `suya'». Otro tanto puede decirse de la opinión de Pascual González, 1995: 780, para quien los méritos alcanzados en la campaña de Haliarto del año anterior habrían hecho a los beocios acreedores del liderazgo en el ejército aliado.

28 Jenofonte habla de tebanos y no de beocios porque su animadversión por los primeros le lleva a ignorar la hegemonía de Tebas sobre el estado federal beocio. Estar en posesión del mando, sobre todo tras su exitosa campaña anterior en Grecia central, parece ser la razón que anida en la remisión beocia, en lugar del temor a encarar a los espartanos que sugiere el sesgado relato de Jenofonte. Acerca de la eficacia de la falange beocia frente a enemigos temibles antes, durante y después de esta batalla, véase Cook, 1981: 318-320.

29 Como señala Tucídides en su narración de la batalla de Mantinea (5.71.1), era natural la tendencia de los hoplitas a desplazarse hacia su derecha, buscando proteger la desguarnecida mitad derecha de su cuerpo con el escudo del compañero, pero aquí las palabras de Jenofonte denotan una maniobra deliberada (puede que, como ha pensado Hamilton, 1979: 222, para evitar dejar un hueco en la línea). 
1

Los ejércitos enfrentados marchan en columna hacia la derecha hasta que desbordan parcialmente la izquierda enemiga y después giran a la izquierda en línea de batalla.

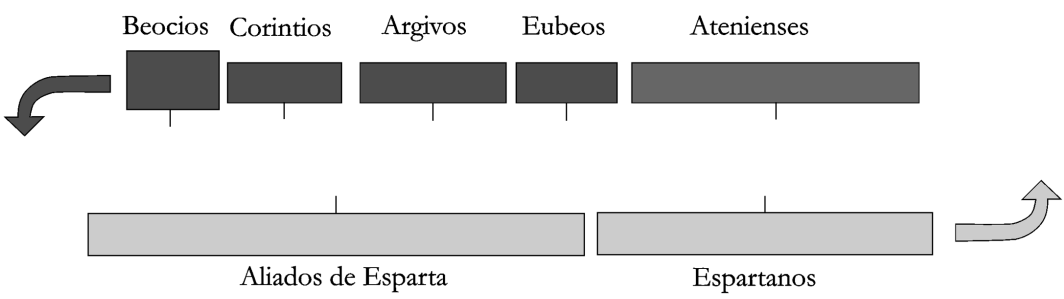

2 La mayoría de los aliados de Esparta huyen al contacto, al igual que los atenienses que encaran a los espartanos.

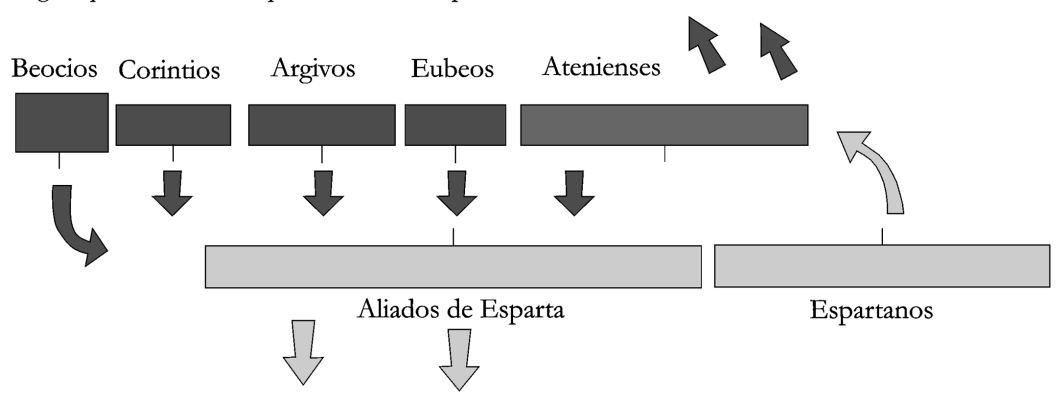

3 Los espartanos varían a la izquierda y arrollan el flanco desprotegido -sin escudo- del enemigo que intenta retirarse.

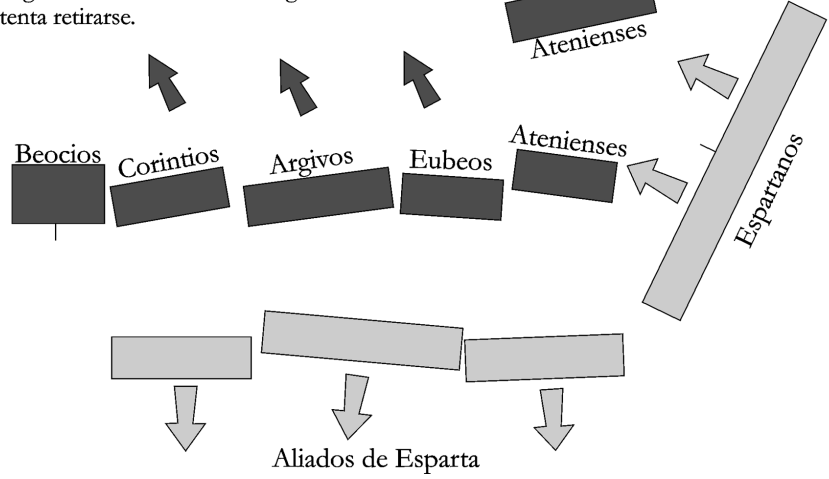

Fig. 2. La batalla de Nemea en tres fases (según Lazenby, modificado)

nienses mientras escapaban ${ }^{30}$. Justamente lo contrario sucedió con sus aliados del ala izquierda, que, a excepción de los peleneos, que resistían con coraje ante los tespios, se dieron a la desbandada, pero los victoriosos espartanos corrieron en su ayuda y, sorprendiendo a sus perseguidores, les atacaron por el costado no cubierto por el escudo ( $\varepsilon \grave{i s} \tau \grave{\alpha} \gamma u \mu \nu \alpha$ ), primero

30 En Lys. 16.15 el joven caballero Mantíteo se enorgullece de haber combatido en primera línea en tanto que otros compañeros hacían por escabullirse, y asegura haberse retirado «después del arrogante Estirieo» (obviamente Trasibulo de Estiria, estratego en Nemea y principal abogado de la alianza con Tebas, quien parece haber vertido duras críticas hacia el comportamiento de sus conciudadanos durante el choque), dando a entender con todo ello la ausencia de un compromiso generalizado o bien cierta falta de ardor entre las filas atenienses. 
a los argivos, luego a los corintios y por último a algunos beocios ${ }^{31}$. Todos ellos acabaron por emprender la huida hacia la ciudad de Corinto, que en un principio no abrió sus puertas, hasta que el empeño de un grupo minoritario de ciudadanos logró desde el interior, frente a la opinión de la mayoría, forzar la apertura y evitar así un número mucho mayor de bajas entre sus aliados ${ }^{32}$. Jenofonte asegura que únicamente ocho espartanos sucumbieron en el choque, aunque reconoce que no fueron pocas las bajas entre sus aliados, en tanto que para Diodoro los lacedemonios y sus aliados dejaron en el campo mil cien hombres por nada menos que dos mil ochocientos de sus enemigos ${ }^{33}$.

Junto al testimonio literario sobre el número de caídos conservamos evidencias de carácter epigráfico. La primera es la fina estela funeraria de mármol blanco proveniente del Cerámico y perteneciente a Dexileo, hijo de Lisanias, del demo de Torico, de la tribu Acamántide, en la que se representa a un jinete en el acto de herir con su lanza a un hoplita enemigo caído $^{34}$. La inscripción nos recuerda que este i años, posiblemente junto con otros cuatro compañeros, en la batalla de Corinto, bajo el arcontado de Eubulides (por tanto entre el 16 de julio de 394 y el 15 de julio de 393), lo que de paso viene a confirmar nuestra datación del choque en la segunda quincena de julio:

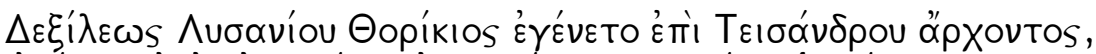

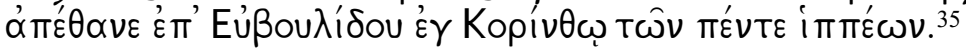

El nombre de Dexileo figura también entre los inscritos en el epistilo del anthémion ornamentado de otra estela contemporánea, cuyo relieve de la parte inferior se ha perdido, que

31 X. HG. 4.2.18-22. Lazenby, 1985: 139-140 acepta el relato de Jenofonte, que considera muy preferible al de Diodoro. Anderson, 1970: 144-150 tampoco alberga dudas acerca del testimonio de Jenofonte e incluso intenta dar respuesta a las lagunas e interrogantes suscitadas por el mismo. Mucho más crítico, Accame, 1951: 78-87 opina empero que el historiador ateniense, en consonancia con sus fuentes, no sólo es hostil a los tebanos y favorable a los espartanos - y en menor medida a los atenienses-, sino que su narración en general «se corresponde poco con la realidad».

32 X. HG. 4.2.23 y sobre todo Dem. 20.52-53; para la interpretación de este episodio a la luz de la stásis o conflicto civil instalado en la ciudadanía corintia, véase Fornis, 2001: 215-217.

33 X. HG. 4.3.1; D.S. 14.83.2. En su Agesilao (7.5) Jenofonte recoge los mismos ocho muertos espartanos frente a ¡diez mil! del enemigo. Sin dar cifras, Plutarco (Ages. 16.6; Mor. 211 e-f) habla de mínimas bajas espartanas y cuantiosas de sus adversarios, así que el propio Agesilao se lamenta por la pérdida de muchas vidas griegas que tan valiosas habrían sido en la conquista del bárbaro. El sentimiento del rey, ciertamente una concesión a la nostalgia del biógrafo, concuerda bien con la tradición espartana que prohibía a sus ciudadanos perseguir largo tiempo a los vencidos en fuga - como sucedió también esta vez-, con lo que se evitaba derramar sangre griega inútilmente, pero al mismo tiempo se pretendía que el enemigo captara el mensaje de que era preferible la huida a la enconada resistencia (Plu. Mor. 228 f; Polyaen. 1.16.3). Otras fuentes fragmentarias como Éforo ( FGrH 70 F 209) y Androción ( FGrH 324 F 47) recuerdan también la contundencia de la victoria espartana. Para una inscripción fragmentaria con las bajas atenienses en Nemea y Coronea, vid. infra y $\mathrm{n}^{\circ} 39$.

34 El relieve de Dexileo es uno de los más famosos dentro del bien documentado tipo de tumba en que se representa una escena de combate, en esta ocasión de un caballero, simbolizando a la vez el ideal aristocrático (kalokagathía) y el valor y entrega por el bien de la comunidad (andragathía). En esta línea Bugh, 1988: 139, seguido por Spence, 1993: 219, ha destacado que este monumento y el siguiente pretendían dejar constancia pública del valor y el servicio a la democracia mostrados por ciertos miembros de la caballería, un cuerpo sobre el que pesaba el estigma de su pasada colaboración con el sangriento régimen de los Treinta Tiranos (en el caso de Dexileo además, su familia quiso grabar la fecha de nacimiento, algo que es excepcional en las tumbas áticas, presumiblemente con el fin de dejar constancia de que era demasiado joven para haber servido bajo los Treinta). Acerca de la impopularidad de la caballería ateniense a principios del siglo IV, cf. Spence, 1993: 216-224. Véase igualmente Clairmont, 1983: 219-221; Stupperich, 1994: 94-95.

$35 I G \mathrm{II}^{2} 6217=$ Tod, 1948: $\mathrm{n}^{\circ} 105=$ Harding, 1985: ${ }^{\circ}$ 19C. Seguimos a Accame, 1951: 73 en pensar que la expre-

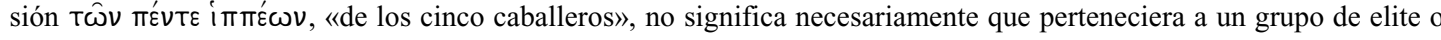
que hubiera ganado especial reconocimiento en alguna acción militar — según hipótesis de historiadores modernos contempladas por Marcus Tod en su comentario a la inscripción-, sino que se entiende mejor como una alusión a cuatro camaradas con los que posiblemente integraba un escuadrón y que también caerían con él, tal y como evidencia el siguiente epígrafe (n. 38): 
recoge una lista oficial de bajas de caballeros atenienses en Nemea y Coronea (un total de once, contando el filarca), posiblemente de la tribu Acamántide — a la que sabemos pertenecía Dexileo y que, a juzgar por las palabras de $\mathrm{Mantíteo}^{36}$, sufrió graves pérdidas en Nemea-, dado que el número de hippeîs del conjunto de las diez tribus atenienses caídos en 394/3, tanto en las dos batallas campales como en otras escaramuzas de menor entidad, debió de ser muy superior si tenemos presente que, según Jenofonte ${ }^{37}$, sólo en Nemea intervinieron seiscientos jinetes atenienses:

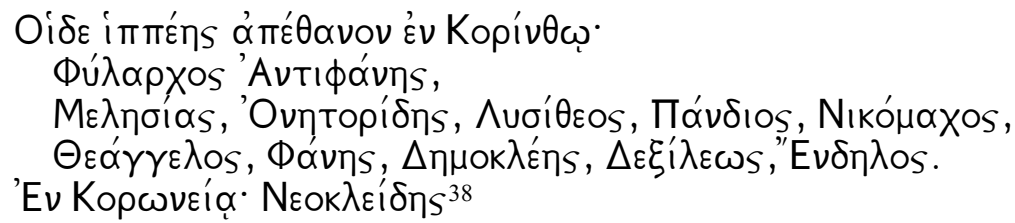

Se ha preservado asimismo la esquina superior derecha de una inscripción que recogía la

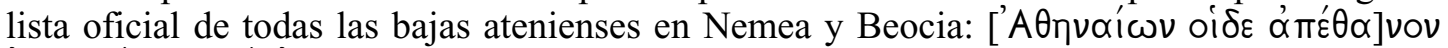

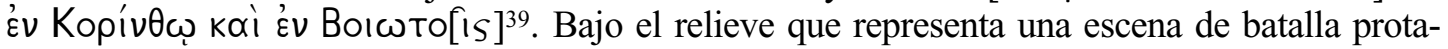
gonizada por caballeros figuraban los nombres de los caídos, pero puesto que apenas ha subsistido algo más que el citado encabezamiento y los nombres oficiales de seis de las diez tribus atenienses, pocas conclusiones se pueden sacar, más allá de que la lista de la tribu Eneide se

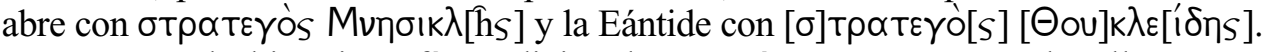

Frente a la historiografía tradicional que veía en Nemea una batalla campal a la vieja usanza, en la que dos masas de infantes pesados colisionaban sin estrategia previa alguna, primero Anderson y luego Lazenby han puesto el énfasis en lo novedoso de la maniobra envolvente de los lacedemonios, pensada y ejecutada con la disciplina y precisión propias del mejor ejército griego, no como en Mantinea, en 418, donde el rey Agis ordenó de forma improvisada y con la falange en movimiento un giro a la derecha de dos batallones lacedemonios para cubrir el hueco abierto entre las dos alas, una maniobra considerada tan arriesgada que de

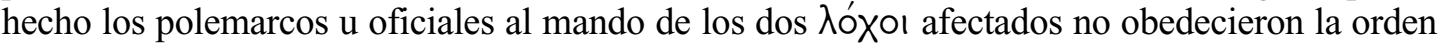
de su comandante ${ }^{40}$. Ahora bien, no debe ser pasado por alto que la puesta en acción de dicha estrategia supuso el sacrificio de los aliados del ala izquierda, en la confianza de que los espartanos serían más rápidos en sacar provecho del desbordamiento de las filas enemigas.

36 Lys. 16.15

$37 H G$. 4.2.17

$38 I G \mathrm{II}^{2} 5222=$ Tod, 1948: $\mathrm{n}^{\circ} 104=$ Harding, 1985: n 19B. La hipótesis, que se remonta a Brueckner, fue recogida por Tod (ibid.) y sucesivamente por Accame, 1951: 74-75; Aucello, 1964: 34 y Funke, 1980: 79 ss. Bugh, 1988: 136139 sospecha que la tribu Acamántide soportó al menos la mitad de las bajas de la caballería ateniense y puede que incluso todas, ya que, de acuerdo con una práctica habitual — de la que Bugh aduce algunos ejemplos-, posiblemente la ciudad no envió a Corinto a caballeros de las diez tribus. Contra Pritchett, 1969: 83 y Strauss, 1986: 123-124, para quienes una cifra tan baja no se explica por su adscripción a una sola tribu, sino por la escasa implicación de la caballería en dos batallas eminentemente hoplíticas (Strauss sugiere incluso que hubo cierta reluctancia al combate por parte de los hippeîs atenienses). Sobre las características del anthémion en sí, Clairmont, 1983: 212-214.

$39 I G \mathrm{II}^{2} 5221$ = Tod, 1948: ${ }^{\circ} 104$ pág. $19=$ Harding, 1985: ${ }^{\circ} 19 \mathrm{~A}$

40 Anderson, 1970: 140-141; Lazenby, 1985: 143 y 1989: 71. Para la peligrosa maniobra espartana en la batalla de Mantinea, véase Fornis, 1999: 81-82 con n. 28 y la bibliografía allí recogida; según Lazenby, 1989: 69, el simple hecho de que Agis contemplara la posibilidad de tal maniobra revela la enorme confianza que cualquier comandante espartano tenía en sus hombres. 


\section{LA BATALLA DE CORONEA}

El rey espartano Agesilao II, llamado de su campaña asiática por los éforos, no tuvo tiempo de regresar al Peloponeso para combatir en Nemea. Las nuevas de la victoria espartana le sorprendieron en Anfípolis, en la Calcídica. Desde allí Agesilao se abrió camino a través de los hostiles troleos tracios, que le exigían cien talentos de plata y cien mujeres por franquearle el paso, amedrentó al rey de Macedonia ${ }^{41}$ al responder con firmeza que continuaría la marcha a través de su territorio mientras el macedonio meditaba si le permitía o no hacerlo y se impuso a la caballería tesalia, considerada la mejor de Grecia (тoús $\mu \varepsilon$ yíotov

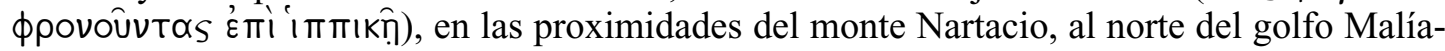
co, victoria ésta que le llenó de orgullo porque ponía en evidencia la eficacia del entrenamiento de sus jinetes ${ }^{42}$.

En el sur de Tesalia el rey espartano se habría encontrado, según Plutarco ${ }^{43}$, con el éforo Dífridas, que había viajado, presumiblemente cruzando el golfo de Corinto, con el objeto de transmitirle la orden de que debía proceder sin dilación a la invasión de Beocia; sin duda, habida cuenta la ruta seguida por Agesilao, los planes habían sido trazados con anterioridad y sólo la urgencia del movimiento constituiría realmente una novedad. De algún modo se recuperaba la estrategia desplegada por Pausanias y Lisandro el año anterior - la que inesperadamente fracasó en Haliarto ${ }^{4}$ _ , es decir, en este caso la apertura de un segundo frente que forzara a la coalición antiespartana a desviar parte de las fuerzas concentradas en el Istmo.

Tampoco hay huella en el relato de Jenofonte de una inusual convocatoria realizada en Esparta para seleccionar cincuenta espartiatas que por su vigor fueran dignos de servir al lado de Agesilao. Además de honrarle, motivo que recoge Plutarco, muy probablemente se pretendía incrementar el número de hómoioi en un ejército que, como el que dirigía el rey euripóntida, estaba integrado fundamentalmente por neodamodes, aliados asiáticos y mercenarios, y que como enseguida veremos por la treta en torno al desenlace de la batalla de Cnido, no le merecían su entera confianza ${ }^{45}$. No en vano parecía estarse dirimiendo la suerte de la guerra en suelo heleno y no la de una campaña en las lejanas tierras asiáticas.

En apenas un mes desde su partida, Agesilao alcanzó la frontera beocia ${ }^{46}$, momento que podemos datar con precisión el día 14 de agosto de 394 gracias a que Jenofonte recuerda un eclip-

41 Aunque Jenofonte no refiere el episodio y Plutarco calla el nombre del monarca, posiblemente se trate de Eropo, a quien, si aceptamos una noticia de Polieno (2.1.17), Agesilao habría engañado haciéndole creer que disponía de un contingente de caballería mucho mayor (Shipley, 1997: 214-215). En este contexto quizá debe situarse una anécdota de dudosa verosimilitud relatada por Plutarco (Mor. 210 d), según la cual Agesilao rechazó los honores divinos que le ofrecían los tasios (otra ocasión que se presta a ello sería la intervención espartana en dicha isla en 385).

42 X. HG. 4.3.1-9 y Ages. 7.5; Plu. Ages. 16. Jenofonte describe a todos los tesalios, salvo los desterrados, como aliados de los beocios, pero no los lista entre las fuerzas del sinedrio que lucharon en Nemea y sabemos que al menos Licofrón de Feras se mostraba favorable a los lacedemonios. En el más prolijo relato de Plutarco, Agesilao, sin parlamento previo, devasta los campos tesalios, prueba de que contaba a priori con su hostilidad; el biógrafo de Queronea, poniendo de manifiesto su acceso a fuentes beocias, narra asimismo un infructuoso intento de ganarse a la ciudad de Larisa mediante dos enviados, Jenocles y Escites, que son sin embargo retenidos y obligan al rey espartano a pactar algún tipo de acuerdo para no demorarse combatiendo por su liberación.

43 Ages. 17.1-2. Jenofonte no dice nada al respecto.

44 X. $H G$. 3.5.6-7 y 17-20.

45 Plu. Ages. 17.3; cf. Shipley, 1997: 222-223. Sobre los neodamodes, véase ahora Fornis, 2003: 270-271, con bibliografía anterior. Cabe recordar que Esparta fue el primer estado griego en utilizar mercenarios de manera masiva (Parke, 1933: 43-48).

46 Jerjes había invertido un año en recorrer la misma distancia (X. Ages. 2.1; cf. Krentz, 1995: 210, para quien el paralelismo refuerza la imagen de «aspirante a conquistador» de Agesilao); según Plutarco (Ages. 17.4), Agesilao estaba ya acampado en Queronea el día del eclipse. Harrison, 1913: 132 pensó que, puesto que Agesilao no encontró oposición a su paso por Heraclea y las Termópilas, Diodoro (14.82.5-10) se había confundido y había pasado la campaña de Ismenias en Grecia central al año 395/4 cuando en realidad habría tenido lugar con posterioridad al verano de 394 (lo que significaría que Heraclea seguía bajo una guarnición lacedemonia), pero por sí mismo no parece un argumento de suficiente peso y 
se solar que se simultanea —en un ejemplo de lo que se conoce como «retribución divina»con las nuevas de la derrota naval de Cnido y la muerte en ella de su cuñado Pisandro, la cual sin embargo ordenó comunicar a sus hombres como una victoria espartana con el objeto de no minar su moral y evitar posibles deserciones, sobre todo entre los griegos de Asia ${ }^{47}$.

El ejército de Agesilao se componía de los tres mil neodamodes y los diez mil hoplitas aliados peloponesios que habían partido hacia Asia primero con Tibrón en 399 y luego con el propio diarca en $396^{48}$, salvo las bajas producidas en este tiempo y los cuatro mil que quedaron como guarnición bajo el mando del harmosta Euxeno, a los que cabe añadir un número indeterminado de griegos jonios, eolios y helespontios y veteranos mercenarios de la campaña de Ciro que trajo consigo desde Asia. A su paso por Grecia central se le fueron incorporando los focidios y una $\mu o ́ p \alpha$ o batallón lacedemonio que tras la batalla de Nemea había cruzado el golfo de Corinto ${ }^{49}$, y ya en territorio beocio lo hicieron el contingente de Orcómeno ${ }^{50}$ y la mitad de la móra lacedemonia acantonada en esta última ciudad. Desgraciadamente el completo silencio de nuestras fuentes nos impide calibrar el tamaño e importancia del ejército de Agesilao, como también el de sus oponentes, que Jenofonte, testigo directo y participante en el choque ${ }^{51}$ - al que califica de «batalla no comparable a ninguna otra de nuestro tiempo»—-, se limita a enumerar: beocios, atenienses, corintios, argivos, enianes, eubeos, locros opuntios y locros ozolas. Así y todo, si aceptamos el testimonio del historiador ateniense, los contingentes de hoplitas y caballeros eran similares — una estimación razonable nos situaría en torno a los veinte mil hoplitas por bando - y sólo en tropas ligeras, reclutadas en las ciudades griegas de Asia Menor sometidas a la hegemonía espartana ${ }^{52}$, era superior en número el ejército de Agesilao ${ }^{53}$.

Cary, 1922 lo desmonta convincentemente; Pascual González, 1995: 786-787 recuerda además que hubo farsalios entre la caballería tesalia que intentó frenar a Agesilao en 394 (X. HG. 4.3.3) cuando hasta la expedición de Ismenias Farsalo había sido aliada de los lacedemonios. Por su parte, Hamilton, 1979: 224 se debate entre la hipótesis de Harrison y una alternativa que salvaría el relato del Sículo: que los coligados, recién derrotados en Nemea, carecieran del tiempo y la moral necesarios para organizar una expedición que defendiera el desfiladero; este último supuesto es también considerado por Cook, 1981: 332-333, quien además añade otros posibles impedimentos: las dificultades inherentes a la coordinación de la leva de fuerzas del sinedrio, la sorpresa de la fácil derrota de la caballería tesalia y el rápido avance de Agesilao y, por último, el tiempo perdido en establecer lugares fortificados en la Corintia. Szemler, 1996: 102-103 cree que la guarnición de Heraclea era suficiente para defender la ciudad, pero no para resistir en las Termópilas a un ejército como el de Agesilao (coincidiendo en este punto con Cook, 1981: 331), quien además elegiría este paso —o bien el camino que sigue las orillas del Calídromo (cf. Plu. Ages. 17.2) - para evitar el hostigamiento o una posible celada de los de Heraclea, mientras que Cook, 1981: 333334 desdeña el testimonio de Plutarco y prefiere el de Jenofonte, que viajaba en la expedición y asegura que, tras derrotar a los tesalios, el rey espartano marchó a través de territorio amigo, lo que eliminaría la ruta por la costa (esto es, a través de una Lócride aliada de Beocia), en beneficio de la ruta interior (por Acaya Ptiótide, Malia, Dóride y Fócide, estados de los cuales sólo el último era aliado, los otros meramente neutrales).

47 X. HG. 4.3.10; Plu. Ages. 17.4-5. Sobre el regreso de Agesilao puede consultarse también los resúmenes de D.S. 14.83.3-4 y Paus. 3.9.12-13. Para la ruta seguida por el rey euripóntida desde Asia, véase Shipley, 1997: 219-221, con bibliografía anterior. Jenofonte no considera reprobable que un comandante mienta a sus hombres si la ocasión lo requiere y aquí la dudosa lealtad de sus tropas asiáticas parece hacerlo imprescindible (Tuplin, 1993: 68).

48 X. $H G$. 3.1.4; 3.4.2.

49 Según Plu. Ages. 17.2, que no menciona la media móra tomada de la guarnición lacedemonia en Orcómeno, fueron dos los batallones llegados desde la Corintia, pero acerca de este punto su relato nunca puede ser preferible al de un Jenofonte que formaba parte del ejército de Agesilao.

50 Vid. supra con n. 16.

51 X. An. 5.3.6; Plu. Ages. 18.2. Según Cartledge, 1987: 60 fue quizá en este momento, al cruzar armas con sus antiguos conciudadanos, cuando Jenofonte sería formalmente exiliado de Atenas por laconismo, en contra de la afirmación de Paus. 5.6.5 de que tal sentencia se remonta a su participación en la campaña de Ciro el Joven y, por tanto, por el cargo de medismo.

52 Parke, 1933: 44-45; Best, 1969: 84.

53 X. HG. 4.3.15-16 y Ages. 2.9. Para Accame, 1951: 89-90 el difícilmente comprensible silencio de Jenofonte abriga la intención de dar mayor relevancia a esta batalla campal, de la que salieron vencedores tanto él mismo como su patrono y mentor Agesilao, que a la anterior de Nemea, donde con toda seguridad el número de fuerzas participantes y 
El enfrentamiento tuvo lugar en la llanura beocia de Coronea, al sur de lago Copais, entre los montes Cefiso y Helicón, a finales de agosto de $394^{54}$ (Fig. 3). Agesilao y sus espartanos ocuparon de nuevo el ala derecha, encarados a los argivos, mientras los orcomenios del ala izquierda quedaban frente a los beocios, que en la defensa del territorio federal habían asumido de modo firme y sin aparente disensión alguna el liderazgo dentro de la coalición y, en consecuencia, el lado derecho de la falange confederada ${ }^{55}$. El resto de los aliados en uno y otro bando se situaron en el centro, en un orden desconocido.

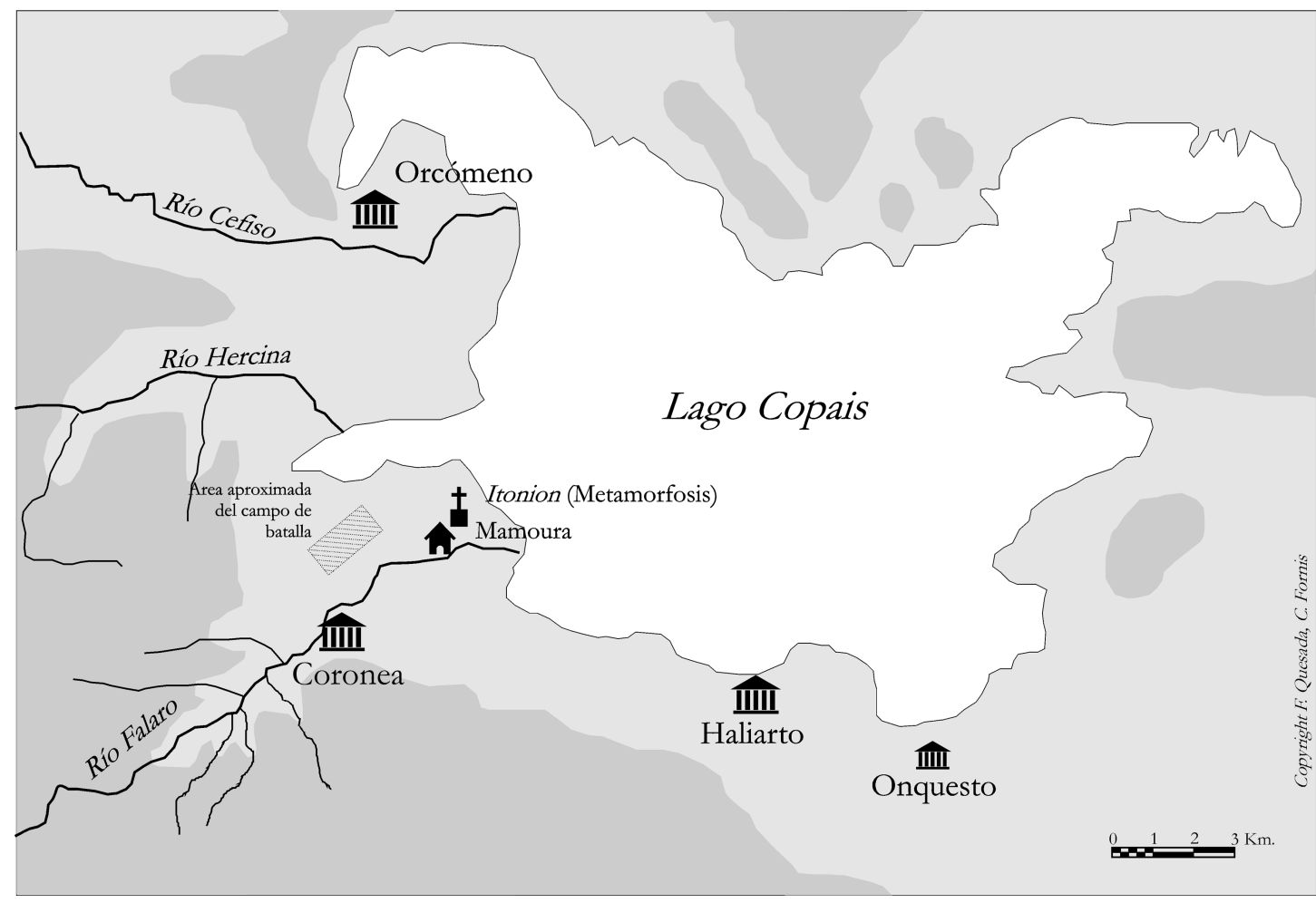

Fig. 3. Topografía del campo de batalla de Coronea (basado en Lazenby)

Un silencio sepulcral presidió la aproximación de ambos ejércitos hasta que, a falta de un estadio - unos 180 metros - para tomar contacto, los tebanos prorrumpieron a lanzar su grito de guerra. Recorrida la mitad de esta distancia, tres pletros, saltaron del centro de la formación lacedemonia los mercenarios de Herípidas, o lo que es lo mismo, los veteranos de

también el de bajas fue superior. En lo que respecta al número de tropas, Accame (ibid.) y Hamilton, 1979: 225 calculan que en Coronea ambos ejércitos debían andar sobre los veinte mil hombres, Buck, 1998: 104 entre los veinte y veinticuatro mil cada uno, mientras Lazenby, 1985: 143-144 estima que Agesilao pudo disponer de unos quince mil hoplitas y los coligados de unos veinte mil. En otro orden de cosas, Lys. 16.16 sirve para constatar que la reciente derrota en Nemea había hecho mella en la moral de la coalición.

54 Coronea era el lugar más propicio para que los coligados cerraran el paso a Agesilao sin el peligro de quedar cercados por tropas provenientes de Orcómeno o Fócide (cf. Pascual González, 1995: 789). Sobre la topografía general del terreno y el probable lugar exacto de la batalla, remitimos de nuevo a Pritchett, 1969: 85-95.

55 Vid. supra con n. 27. Es ésta razón mucho más poderosa y documentada en nuestras fuentes que la sugerida por Cook, 1981: 337-338 en cuanto a que los atenienses pudieron haber quedado relegados en el mando debido a las críticas sufridas por su insuficiente ardor ante el empuje de los lacedemonios en Nemea. 
Ciro, seguidos de los jonios, eolios y helespontios, que provocaron la retirada de quienes se les enfrentaban ${ }^{56}$. Los argivos no esperaron siquiera la embestida de los espartanos de Agesilao y emprendieron la huida hacia las faldas del Helicón. Cuando ya los mercenarios coronaban a Agesilao, llegó la noticia de que los tebanos - más plausiblemente el conjunto de los beocios (supra n. 28)-, encorajinados en la defensa de su propio territorio, habían atravesado las filas de los orcomenios y se habían plantado entre los portadores del bagaje, donde, además de provisiones y equipamiento, se guardaba el preciado botín tomado a los persas en Asia Menor, no menos de mil talentos, vitales ahora que la derrota de Cnido había privado a Esparta, carente de tesoro o caja común en la liga del Peloponeso, del tributo de la mayor parte de Jonia y las islas ${ }^{57}$. Inmediatamente el rey hizo rotar la falange lacedemonia —en una maniobra ensayada y ejecutada a la perfección en medio del combate que se conoce como «contramarcha laconia»" ${ }^{58}$ (Fig. 4) - y la dirigió contra los beocios, de frente y no por la retaguardia, lo que suscita el vehemente elogio de Jenofonte a la nobleza de su héroe y patro-

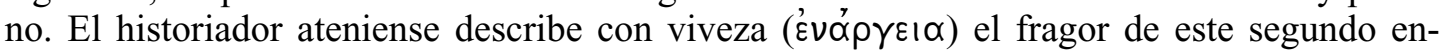
cuentro, una especie de batalla dentro de la batalla que confiere a Coronea una cierta singularidad dentro de los enfrentamientos hoplíticos ${ }^{59}$ : «chocaban los escudos y, al atacar, [los hombres] combatían, mataban y morían». Finalmente algunos de los beocios huyeron hacia el Helicón - cosa que sólo pudieron hacer atravesando las filas lacedemonias, lo que es obviado-, otros muchos fueron muertos y unos ochenta encontraron refugio en el santuario de Atenea Itonia ${ }^{60}$. De nuevo con veneración, Jenofonte afirma que un Agesilao cubierto de heridas no se olvidó de la divinidad y permitió a los suplicantes salir sin daño alguno ${ }^{61}$.

Más escueto, el relato de Diodoro es similar al de Jenofonte, bien que en él no hallamos rastro del papel fundamental desempeñado por los cireos - entre los que se encontraba el propio Jenofonte, no lo olvidemos - y las ciudades asiáticas, como tampoco de la vergonzosa huida de los argivos - sempiternos enemigos de los espartanos en la lucha por la hege-

56 Según Best, 1969: 85 el ataque de Herípidas responde a las tácticas habituales que buscaban romper la falange enemiga a través de la acción de tropas de choque que mezclan hoplitas y peltastas. Entre los aliados que huyeron ante la acometida de los cireos estarían los atenienses, quizá mandados de nuevo por Trasibulo, cuyo prestigio acusó el poco glorioso papel desempeñado por sus hombres, lo que le costó no ser reelegido para la estrategia y caer temporalmente en desgracia frente a los éxitos de su adversario político Conón, vencedor en Cnido (cf. Buck, 1998: 104-105). Parke, 1933: 47 y Marinovic, 1988: 55 han destacado que Coronea fue la primera batalla de la historia griega en la que ambos bandos emplearon mercenarios sobre suelo griego, además con cierta prominencia de creer a Jenofonte.

57 Como apunta Carledge, 1987: 218, el enorme botín amasado durante sus dos años de campaña asiática constituía el principal fruto de la misma. No hay indicio alguno que apunte a que Agesilao dejó el botín custodiado en Orcómeno, como sugiere Pascual González, 1995: 788, de Jenofonte se desprende que los beocios se habían entregado ya al saqueo antes de reorganizarse y encarar a la falange lacedemonia.

58 La contramarcha lacedemonia o laconia es descrita por X. Lac. 11.8. La pericia en la ejecución de la maniobra debe acreditarse más al entrenamiento y disciplina de la falange lacedemonia que al talento en el generalato de Agesilao. Acerca de este último, el juicio de un historiador militar como Anderson, 1970: 153, seguido por Cartledge, 1987: 222, es tan severo como para afirmar que «se limitó a situar a sus hombres donde el enemigo tendría que combatir o huir».

59 En este sentido cabría entender la afirmación de Jenofonte en cuanto a que Coronea fue una batalla sin par en su tiempo, y no en virtud del número de fuerzas implicadas o de bajas sufridas por cualquiera de los contendientes (vid. supra). Si hablamos de trascendencia o consecuencias derivadas de una batalla, fue sin lugar a dudas Leuctra, en 371 , la más decisiva en vida de Jenofonte (Hamilton, 1991: 106).

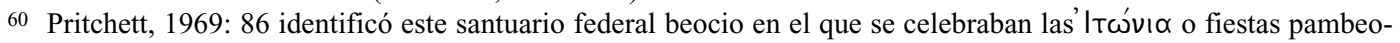
cias en honor de Atenea con la actual capilla de Metamorfosis, a un kilómetro de la moderna aldea de Mamoura (véase Fig. 4). Cf. también Pascual González, 1995: 790-795.

61 X. HG. 4.3.16-20; cf. X. Ages. 2.6-14, con leves diferencias registradas por Accame, 1951: 67-70. Lazenby, 1985: 146 sospecha que Agesilao atacó frontalmente porque poseía una superioridad de más de dos a uno sobre los beocios y porque buscaba una victoria aplastante, definitiva, que de otra forma no se lograría. Para Cartledge, 1987: 221 «el odio hacia los tebanos fue más fuerte que cualquier fría consideración táctica». En la misma línea, Hamilton, 1991: 108-109 hace hincapié en el hecho de que el rey no sólo arriesgó su vida de forma innecesaria — más que valentía, parece estupidez-, sino toda la campaña, evocando ejemplos como los de Lisandro en Haliarto o Cleómbroto en Leuctra. 
monía del Peloponeso- antes de trabar combate ${ }^{62}$. El Sículo aporta además la cifra de muertos en uno y otro bando: más de seiscientos entre la coalición antiespartana, beocios en su mayoría, por trescientos cincuenta del lado de los lacedemonios y sus aliados, unos números bastante admisibles y relativamente bajos para la magnitud del choque, menos cruento de lo que denota el pasaje de Jenofonte con el que abrimos este trabajo ${ }^{63}$.

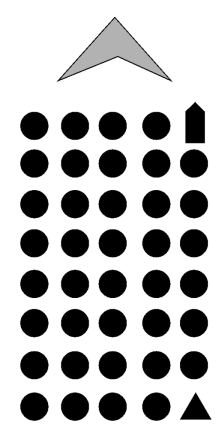

Fase 1: La falange, marchando hacia el norte en orden cerrado, oye que el enemigo se aproxima por retaguardia.

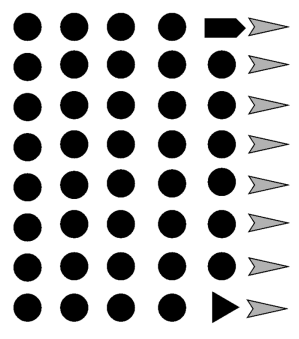

Fase 2: La falange abre sus filas y cada hombre da media vuelta.

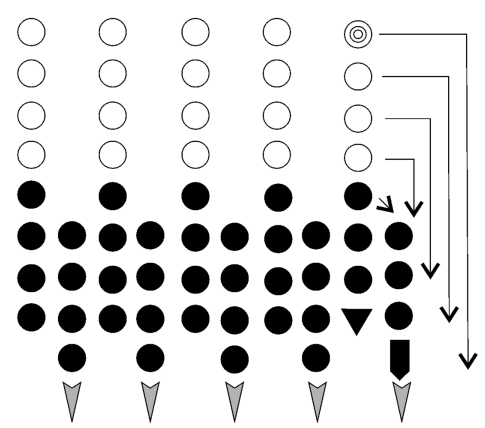

Fase 3: Mientras el último hombre de cada fila $\nabla$ permanece quieto, el primero conduce al resto para colocarse ante $\nabla$
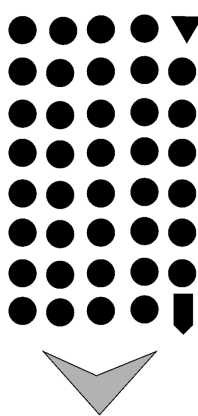

Fase 4: La falange cierra sus filas, ahora mirando al sur, creando el efecto de que avanza sobre el enemigo.

Fig. 4. La contramarcha laconia (según Lazenby, modificado)

En su Vida de Agesilao Plutarco ofrece una versión coincidente con la jenofóntica en la primera parte - salvo por el detalle de que tampoco se alude a la decisiva embestida de los veteranos de Herípidas y de los griegos asiáticos-, pero difiere de la misma en la segunda, bastante menos gloriosa para Agesilao, en la que los lacedemonios se ven forzados a abrir sus filas y a dejar pasar por el medio a los tebanos - más bien beocios, aquí bien organizados y no atemorizados y a la desbandada como en Jenofonte- para después atacarlos por el flanco, por tanto lateral y no frontalmente. Estos últimos, pese a sus elevadas bajas, se retiran en perfecto orden hasta ganar las faldas del Helicón. El propio rey euripóntida sólo salva la

62 Lo que induce a Accame, 1951: 94 a pensar que Jenofonte coloreó su narración de los hechos de acuerdo con sus intereses. También Pascual González, 1995: 797 n. 176 habla de exageración en nuestro historiador, aduciendo que sería muy extraño que los beocios hubieran atacado a los orcomenios mientras contemplaban la huida de sus aliados argivos.

63 D.S. 14.84.1-2. Krentz, 1985: 18-19 señala que Agesilao perdió 1.8\% de sus efectivos, mientras los confederados un 3\% (una ratio de 1:1.7), porcentajes llamativamente bajos en relación con la media de los combates hoplíticos en el período clásico (un 5\% de caídos en el bando vencedor, un 14\% en el vencido, lo que da una ratio de 1:2.9 según el cuadro diseñado por Krentz, que recoge un total de diecisiete batallas entre los años 472 y 371) que el autor explica porque tanto los lacedemonios de un lado como los beocios de otro rompieron las líneas enemigas — de argivos y orcomenios, respectivamente - sin apenas resistencia y sólo al final el duelo entre lacedemonios y beocios resultó más sangriento. Sobre la poco iluminadora inscripción que recogía la lista oficial de bajos atenienses en Nemea y Cotonea, vid. supra y n. 39. 
vida por la bravura y resolución de cincuenta espartiatas selectos que servían como cuerpo de guardia. Siendo Plutarco un beocio de Queronea, no debe extrañar que en su narración sean sus compatriotas quienes se comporten con heroicidad y al final manifiesten con orgullo que su contingente, tras romper por dos veces el frente enemigo y batirse encarnizadamente con lo más granado del ejército espartano, en realidad no había sido vencido ${ }^{64}$.

También Polieno y Frontino discrepan de Jenofonte en cuanto al enfrentamiento entre lacedemonios y tebanos ${ }^{65}$. Al igual que Plutarco, ambos aseguran que los primeros abrieron las filas para que los segundos pasaran a través, mas el ataque posterior no llega en esta ocasión desde el flanco, sino desde la retaguardia - lo que provoca una gran matanza entre los tebanos-, una idea que, de acuerdo con Jenofonte, Agesilao habría descartado al principio ${ }^{66}$. Pero además, poco más adelante Polieno se hace eco de una estratagema de Agesilao para socavar el ánimo de sus enemigos. Cuenta el macedonio que, llegada la noche e interrumpida la batalla —otra novedad con respecto al relato de Jenofonte-, el euripóntida ordenó cubrir de tierra los cadáveres de los espartanos, de modo que, a la mañana siguiente, los beocios vieron tendidos sobre el campo muchos más cuerpos de compañeros que de oponentes y desistieron de reanudar la lucha, detalle revelador de que la victoria distaba de ser decisiva ${ }^{67}$.

Formalmente nadie podía hurtar la victoria a los lacedemonios, por más que no fuera concluyente, en la medida en que habían quedado dueños del campo, erigido el correspondiente trofeo y, de acuerdo con las órdenes de su rey, desfilado con coronas al son de las flautas, en actitud desafiante hacia el enemigo, pero los beocios rehusaron reanudar el combate y enviaron heraldos para reclamar los muertos en señal de reconocimiento oficial de la derrota ${ }^{68}$.

Prueba de la indefinición de la nueva victoria de las armas espartanas es que, en lugar de proseguir la invasión de Beocia, Agesilao se retiró a Delfos, no sólo con el propósito de descansar y reponerse de sus serias heridas, sino también para, fiel a su propaganda, dedicar a Apolo el diezmo del botín conseguido, no menos de cien talentos, y presenciar los juegos píticos de septiembre de $394^{69}$. A fin de no abandonar a su suerte a sus aliados de Grecia central, el rey dejó en Fócide al polemarco Gilis, quien en el curso de una razzia en Lócride encontró la muerte junto a su ayudante Peles y dieciocho espartiatas en una emboscada tendida por tropas ligeras de los locros. Finalmente, Agesilao licenció al ejército y regresó a Esparta, una vez más por vía marítima, cruzando el golfo de Corinto, ya que la terrestre le seguía vedada por la ocupación confederada del Istmo ${ }^{70}$.

64 Plu. Ages. 18. Como apostilla Shipley, 1997: 234, las divergencias entre los relatos de Jenofonte y Plutarco nacen de la fuente local beocia utilizada también por este último. Al igual que previamente con la batalla de Haliarto y más tarde con la de Tegira, Plutarco se recrea en el recuerdo de tradiciones, leyendas y oráculos de su tierra beocia.

65 Polyaen. 2.1.19; Front. 2.6.6.

66 Con todo, para Cartledge, 1987: 221 la descripción de Jenofonte suena más verídica que las versiones de las fuentes tardías.

67 Polyaen. 2.1.23.

68 X. HG. 4.3.21 y Ages. 2.15-16; Plu. Ages. 19.3. Según Accame, 1951: 93, para quien «la vittoria tattica è di Agesilao, ma quella strategica dai Tebani», el rey quiso con estas celebraciones convencerse a sí mismo y a los demás de la victoria. En similares términos se expresa Shipley, 1997: 238. También Cook, 1981: 340-341 considera que el rey espartano fue en la práctica derrotado, pues se vio obligado a parar su invasión de Beocia y la situación en Grecia central siguió siendo bastante favorable a los tebanos, si bien luego matiza tal conclusión con el alegato de que los beocios habían perdido la oportunidad de resolver la guerra con una batalla campal que dejara constancia de la fuerza de su ejército hoplítico, cediendo a partir de este momento su protagonismo a los atenienses.

69 Es obvio por la importancia del botín — mil talentos- que se trata de los frutos obtenidos de las campañas asiáticas y no únicamente del despojo de los cadáveres enemigos en Coronea, pero lo cierto es que, como apunta Accame, 1951: 93, Jenofonte se cuida mucho de aclararlo, posiblemente para exaltar aún más la victoria en tierras beocias.

70 X. HG. 4.3.21-4.1; Plu. Ages. 19.4. 


\section{CONCLUSIÓN}

A modo de conclusión podemos decir que, con colmar el orgullo militar de Esparta e infligir un daño moral a la coalición antilacedemonia, el triunfo de sus armas en los campos de Nemea y Coronea no trajo consigo ventajas estratégicas y casi puede hablarse de victorias técnicas. La primera no había dado a Esparta el control del istmo de Corinto, la llave del Peloponeso y por ello mismo crucial para ganar la contienda, mientras que la segunda no mejoró la situación en Grecia central, área que, a excepción de Fócide y de la rebelde Orcómeno, seguía bajo la influencia del estado federal beocio.

En términos geoestratégicos estas grandes batallas campales dejaron paso a una fase de estancamiento, pero a la vez de desgaste y depredación, dentro de la guerra de Corinto. Se había llegado a un punto muerto en el que ambos bandos conservaban sus posiciones en el istmo - los aliados en torno a Corinto, los lacedemonios con base en Sición- y se limitaban a escaramuzas de escasa consideración, siendo el elevado coste económico consumido por guarniciones y mercenarios - es obvio que los ciudadanos campesinos no podían servir de manera permanente fuera de las fronteras y desatender sus campos ${ }^{71}$ - el principal gravamen para los contendientes ${ }^{72}$.

CÉSAR FORNIS*

Departamento de Historia Antigua. Facultad de Geografia e Historia. Universidad de Sevilla C/ Doña María de Padilla s/n-41004 Sevilla.cfornis@us.es

\section{BIBLIOGRAFÍA}

ACCAME, S. (1951): Ricerche intorno alla guerra corinzia, Nápoles. les.

Anderson, J. K. (1970): Military Theory and Practice in the Age of Xenophon, Berkeley-Los Ánge-

AuCELLO, E. 1964: «Ricerche sulla cronologia della guerra corinzia», Helikon 4, 29-45.

Best, J. P. G. (1969): Thracian Peltasts and their Influence on Greek Warfare, Groninga.

BuCK, R. J. (1998): Thrasybulus and the Athenian Democracy. The Life of an Athenian Statesman, Historia Supl. 120, Stuttgart.

Bugh, G. (1988): The Horsemen of Athens, Princeton.

Cartledge, P.A. (1979): Sparta and Lakonia. A Regional History 1300-362 B.C., LondresBoston-Henley.

(1987): Agesilaos and the Crisis of Sparta, Baltimore.

CARY, M. (1922): «Heracleia Trachinia», $C Q$, 16: 98-99.

CAVAignac, E. (1925): «A propos de la bataille du torrent de Némée», REA, 27: 273-278.

Clairmont, C. W. 1983: Patrios Nomos. Public Burial in Athens during the Fifth and Fourth Centuries B.C., Oxford.

CooK, M. L. (1981): Boeotia in the Corinthian War. Foreign Policy and Domestic Politics, Tesis Doctoral de la Universidad de Washington.

71 Parke, 1933: 50.

72 X. $H G$. 4.4.14.

* Agradezco al Prof. Fernando Quesada su ayuda y paciencia en el diseño de las figuras. 
Cozzoli, U. (1979): Propietà fondiaria ed esercito nello stato spartano dell'età classica, Roma.

DUCREY, P. (1985): Guerre et guerriers dans la Grèce antique, Friburgo (hay reimpresión con estado de la cuestión bibliográfica: París, 1999).

FigueIRA, T. J. (1986): «Population Patterns in Late Archaic and Classical Sparta», TAPhA, 116: $165-213$.

FoRNIS, C. (1999): Estabilidad y conflicto civil en la guerra del Peloponeso. Las sociedades corintia y argiva, BAR IS 762, Oxford.

(2001): «Identidad corintia e identidad argiva en la 'unión' de 392-386 a.C.», en P. López Barja y S. Reboreda (eds.), Fronteras e identidad: III Reunión de Historiadores del Mundo Griego Antiguo (Santiago de Compostela-Trasalba, 25-27 de Septiembre de 2000), Santiago de CompostelaVigo: 207-226.

(2003): Esparta. Historia, sociedad y cultura de un mito historiográfico, Barcelona.

Funke, P. (1980): Homónoia und Arché. Athen und die griechische Staatenwelt vom Ende des Peloponnesischen Krieges bis zum Königsfrieden (403-387/6 v. Chr.), Historia Supl. 37, Wiesbaden.

Hamilton, C. D. (1979): Sparta's Bitter Victories. Politics and Diplomacy in the Corinthian War, Ítaca-Londres.

(1991): Agesilaus and the Failure of Spartan Hegemony, Ítaca-Londres.

Hanson, V. D. (1989): The Western Way of War. Infantry Battle in Classical Greece, Nueva York. (ed.) (1991): Hoplites. The Classical Greek Battle Experience, Londres.

HARDING, Ph. (1985): From the End of the Peloponnesian War to the Battle of Ipsus, Translated Documents of Greece and Rome 2, Cambridge, 1985.

HARrison, E. (1913): «A Problem in the Corinthian War», CQ, 7: 132.

KRENTZ, P. (1985): «Casualties in Hoplites Battles», GRBS, 26: 13-20.

(1995): Xenophon: Hellenika II.311.-IV.2.8. Edited with an Introduction, Translation and Commentary, Warminster.

Kromayer, J. y VeIth, G. (1931): Antike Schlachtfelder, IV, Berlín.

LAZENBY, J. (1985): The Spartan Army, Warminster.

(1989): «Hoplite Warfare», en J. Hackett (ed.), Warfare in the Ancient World, Nueva York-Oxford-Sydney: 54-81.

Legon, R. P. (1967): «Phliasian Politics and Policy in the Early Fourth Century B.C.», Historia, 16: 324-337.

LissarRague, F. (1990): L'autre guerrier. Archers, peltastes, cavaliers dans l'imaginerie attique, París-Roma.

MARINOVIC, L. P. (1988): Le mercenariat grec au IVe siècle avant notre ère et la crise de la polis, Annales Littéraires de l'Université de Besançon 372, París (el original ruso es de 1975).

OBER, J. (1996): «The Rules of War in Classical Greece», en Id., The Athenian Revolution. Essays on Ancient Greek Democracy and Political Theory, Princeton: 53-71.

PARKe, H. W. (1930): «The Development of the Second Spartan Empire (395-371 B.C.)», JHS, 50: $37-79$. (reimpr. 1975).

(1933): Greek Mercenary Soldiers. From the Earliest Times to the Battle of Ipsus, Oxford

Pascual GonzÁlez, J. (1995): Tebas y la confederación beocia en el periodo de la Guerra de Corinto (395-386 a.C.), Tesis Doctoral microfilmada de la Universidad Autónoma de Madrid. 
PritchetT, W. K. (1969): Studies in Ancient Greek Topography, II. Battlefields, Berkeley-Los Ángeles.

RoY, J. (1971): «Tegeans at the Battle near the River Nemea in 394 B.C.», PP, 26: 439-441.

SAlmon, J. B. (1984): Wealthy Corinth. A History of the City to 338 B.C., Oxford.

ShIPLEY, D. R. (1997): Plutarch's Life of Agesilaos. Response to Sources in the Presentation of Character, Oxford.

SNODGRASs, A. M. (1967): Arms and Armor of the Greeks, Londres (hay reimpresión con «afterword» bibliográfico: Baltimore-Londres, 1999).

Spence, I. G. (1993): The Cavalry of Classical Greece. A Social and Military History with Particular Reference to Athens, Oxford.

Strauss, B. S. (1986): Athens after the Peloponnesian War. Class, Faction and Policy, 403-386 B.C., Londres.

STUPPERICH, R. (1994): «The Iconography of Athenian State Burials in the Classical Period», en W.D.E. Coulson et alii (eds.), The Archaeology of Athens and Attica under the Democracy, Oxbow Monograph 37, Oxford, 93-103.

SzemLeR, G. J. (1996): «Two Notes on the Corinthian War», AncW, 27: 95-104.

ThOmpson, W. E. (1970): «The Politics of Phius», Eranos, 68: 224-230.

ToD, M. N. (1948): A Selection of Greek Historical Inscriptions, II. From 403 to 323 B.C., Oxford.

TuPLIN, C. (1986): «Military Engagements in Xenophon's Hellenica», en I. S. Moxon, J. D. Smart y A. J. Woodman (eds.), Past Perspective. Studies in Greek and Roman Historical Writing, Cambridge: 37-66.

(1993): The Failings of Empire. A Reading of Xenophon Hellenica 2.3.11-7.5.27, Historia Supl. 76, Stuttgart.

VALZANIA, S. (1996): «L'esercito spartano nel periodo dell'egemonia: dimensioni e compiti statregici», $Q S, 43: 19-72$.

WelweI, K.-W. (1974): Unfreie im antiken Kriegsdienst I. Athen und Sparta, Wiesbaden. 